\title{
Development and Application of Molecular Simulation Methods for the Screening of Industrial Zeolite Adsorbents
}

\author{
A.H. Fuchs' ${ }^{1}$, A. Boutin ${ }^{1}$, J.-M. Teuler ${ }^{1}$, A. Di Lella ${ }^{1}$, A. Wender' ${ }^{2}$, \\ B. Tavitian ${ }^{2}$ and P. Ungerer ${ }^{2}$ \\ 1 Laboratoire de Chimie Physique (LCP), Université de Paris Sud and CNRS - France \\ 2 Institut français du pétrole, 1 et 4, avenue de Bois-Préau, 92852 Rueil-Malmaison Cedex - France \\ e-mail: alain.fuchs@enscp.fr - anne.boutin@lcp.u-psud.fr - jean-marie.teuler@lcp.u-psud.fr - dilella@lcp.u-psud.fr - aurelie.wender@ifp.fr \\ bernard.tavitian@wanadoo.fr - philippe.ungerer@ifp.fr
}

\begin{abstract}
Résumé - Mise au point de méthodes de simulation moléculaire en vue de la sélection d'adsorbants zéolithiques industriels - Plusieurs opérations industrielles recourent à des zéolithes comme adsorbants : séparation des aromatiques, séparation des isoalcanes à fort indice d'octane, élimination des composés soufrés des carburants. Une étape limitante dans la recherche des zéolithes appropriées pour ces procédés est la difficulté de prédire les comportements d'adsorption au moyen des modèles thermodynamiques classiques, ce qui requiert d'explorer de nombreuses possibilités par la voie expérimentale avant que des améliorations significatives soient obtenues.

De manière à apporter une solution générale à ce type de problèmes, nous avons implanté des méthodes de simulation adaptées à une grande variété de systèmes. Divers types de biais statistiques (biais configurationnel, biais de réservoir) ont été associés au « parallel tempering » pour procurer un échantillonnage efficace de toutes les configurations possibles, y compris quand la mobilité des cations est considérée en même temps que l'adsorption de molécules. Les calculs d'énergie comprennent à la fois des contributions apolaires et électrostatiques. Ces possibilités sont regroupées dans un code de Monte Carlo unique, appelé GIBBS, qui peut prendre en compte des molécules linéaires, ramifiées, cycliques ou des molécules flexibles de forme plus complexe. Un effort particulier a été consacré au développement d'un champ de force polyvalent pour évaluer les interactions zéolithe-molécule.

Le recours à ces méthodes est illustré par plusieurs exemples dans lesquels les résultats sont confrontés à des données expérimentales. Un premier exemple se rapporte à la compréhension du positionnement des cations dans les faujasites et son interaction avec l'adsorption de l'eau. Un deuxième exemple a trait à l'adsorption de $n$-alcanes dans les faujasites, où la prise en compte de l'énergie de polarisation permet une bonne transférabilité du potentiel zéolithe-alcanes. Enfin, nous discutons l'adsorption compétitive d'alkylmercaptans et des autres composants d'un gaz naturel à haute pression.

Bien que ces méthodes de Monte Carlo méritent encore de nombreuses améliorations, elles procurent d'ores et déjà une contribution significative à la compréhension générale de l'adsorption compétitive et à la mise au point de meilleurs procédés.
\end{abstract}

Abstract - Development and Application of Molecular Simulation Methods for the Screening of Industrial Zeolite Adsorbents - Numerous industrial operations involve zeolite adsorbents: separation of aromatics, separation of high-octane branched alkanes, and purification of fuels from sulphur-bearing compounds, among others. A limiting step in searching for appropriate zeolites to improve these 
processes is the poor capacity of classical thermodynamic models to predict adsorption behavior, thus requiring the exploration of many unsuccessful possibilities by experimental means before significant improvements are found.

In order to provide a general answer to this problem, molecular simulation methods have been developed to address a large array of systems. Various types of statistical bias (configurational bias and reservoir bias) have been associated with parallel tempering to provide efficient sampling of all possible configurations, including when cation mobility is considered together with molecular adsorption. Both nonpolar and electrostatic contributions to energy have been considered. These features are available in a single Monte Carlo software, named GIBBS, which may consider either linear, branched, cyclic or more complex flexible molecules. A special effort has also been devoted to the development of a multipurpose force field to evaluate guest-host interactions.

The contribution of these methods is illustrated by several examples in which their results are confronted with available experimental data. The first example pertains to the understanding of cation location in faujasites and its interplay with the adsorption of water. The second example pertains to the adsorption of alkanes in faujasites, where the account of polarization energy allows a good transferability of guesthost potential. Lastly, we consider the competitive adsorption of traces of alkanethiols with the other components of a multicomponent natural gas in high-pressure conditions.

Although these Monte Carlo methods still merit numerous improvements, they are already providing a very significant contribution to the general understanding of competitive adsorption and to the design of better processes.

\section{INTRODUCTION}

Separation processes based on adsorption in zeolites have become a key tool in the oil and gas industry. They are used to perform operations requiring a high selectivity versus chemical structure, that would be more difficult with distillation or solvent-based processes [1]. Prominent applications are the separation of branched alkanes from $n$-alkanes, aimed at producing fuels of high-octane number, and the separation of aromatic isomers for the production of paraxylene, an important intermediate in the industrial synthesis of polystyrene. Adsorption is also used for purifications, i.e. the removal of trace contaminants. Gas dehydration is a wellknown application of this kind, but the selective removal of sulfur compounds from natural gases or from fuels is also a potentially interesting use of adsorption processes.

The basic reason why physisorption in zeolites is so selective to the chemical structure of guest molecules is the comparable size of their pores-generally less than 1.3 nanometers-with molecular dimensions and the specific energetic interaction between the zeolitic framework and the sorbed compounds. While the diversity of pore sizes and crystalline structures [2] produces a range of possible effects in which entropy plays a large role, the substitution of silicium by aluminium and the associated presence of charge-compensating cations in the micropores [3] produce a variety of other effects, in which the energetic aspects of polar interactions between the zeolite and guest molecules play a large role.

Unlike distillation processes where excellent models are available to predict pure component properties and activity coefficients in fluid mixtures, there is no classical thermodynamic theory that is sufficiently reliable to predict adsorption properties, either for pure compounds or for mixtures. Some simple models are successful in correlating the behavior of known systems, but they are generally unable to provide a reasonable estimate of adsorption isotherms from the molecular structure of the adsorbate and from the crystalline structure of the zeolite. They are also unable to predict adsorption selectivity in mixtures, particularly the changes in selectivity which result from modifications of the silicon to aluminium ratio or of the charge-compensating cation. Up to now, the development of adsorption processes has thus been based on numerous experiments, with an associated duration and cost that limits the development of this technology.

This is why molecular simulation has been identified as the necessary theoretical tool to understand the basis of adsorption selectivity and to improve the screening of possible adsorbents when a given separation target is assigned [4]. At the academic level, molecular simulation has successfully dealt with representative adsorption problems, using Monte Carlo techniques [5-9]. This has allowed linear and branched alkane adsorption for a significant range of zeolites to be addressed [10-15]. Meanwhile, our group has investigated the adsorption of aromatics in faujasites, a delicate problem in which the location of cations and the electrostatic interactions play a major role $[16,17]$. The location of cations is also a delicate issue, because it is not always available from experimental measurements and it may be influenced by the presence of water, which is often co-adsorbed in laboratory measurements or in industrial processes. Application of Monte Carlo techniques has provided encouraging answers to this problem [18-20].

However, there are still important pending issues to make molecular simulation a really versatile tool for industrial 
applications. Regarding algorithms, it is desirable to benefit from more efficient algorithms to sample molecular conformations and cationic locations. Regarding zeolite-molecule interactions, there is an important need for a general, reasonably accurate force field that applies to a large range of molecules and zeolites. Both issues will be considered in the present article. In the first part, we will briefly present the simulation methods that we use, and particularly a specific Monte Carlo move to obtain the equilibrium distribution of cations more quickly and more reliably. In the second part, we will show a few applications, in which we will try to illustrate the capacity of available force fields to model consistently the adsorption properties of hydrocarbons as well as of polar species.

\section{SIMULATION METHODS}

The results shown in this article were obtained by Grand Canonical Monte Carlo simulation, considering the aluminated siliceous framework as immobile. Cations may be either considered as a mobile species, in the same way as guest molecules, or as fixed. In all cases, the interaction energy of mobile species with the fixed framework are computed at the nodes of a fixed grid with regular spacing, which covers the whole unit cell. Interpolating between these tabulated energies allows for an efficient simulation of the Grand Canonical ensemble (Fig. 1).

The following contributions to the potential energy are considered:

- dispersion and repulsion energy;

- bending and torsional energy of flexible molecules such as $n$-alkanes;

- electrostatic energy, using point charges on the framework and on molecules;

- polarization energy, arising from the polarization of mobile species in the electric field created by the zeolite and by surrounding species.

Dispersion and repulsion are modeled with a LennardJones 6-12 functional form for neutral mobile species. We use all atoms in the case of aromatics [21] or $\mathrm{CO}_{2}$ [22], united atoms in the case of water [23] and anisotropic united atoms in the case of organic compounds such as alkanes or organic thiols [24-26]. A Buckingham exp-6 potential [20] is used in the specific case of cation-framework interactions.

Electrostatic energy is neglected when non-polar molecules such as alkanes are considered, but it is included when the
Step 1: determination of chemical potentials $\mu_{\mathrm{i}}$ in the fluid phase by biased test insertions in a NPT simulation

Step 2: calculation of solid-guest interaction energy on a grid

Step 3: Grand Canonical simulation in the solid at fixed $\mu_{\mathrm{i}}, \mathrm{V}, \mathrm{T}$

+ configurational bias or reservoir bias
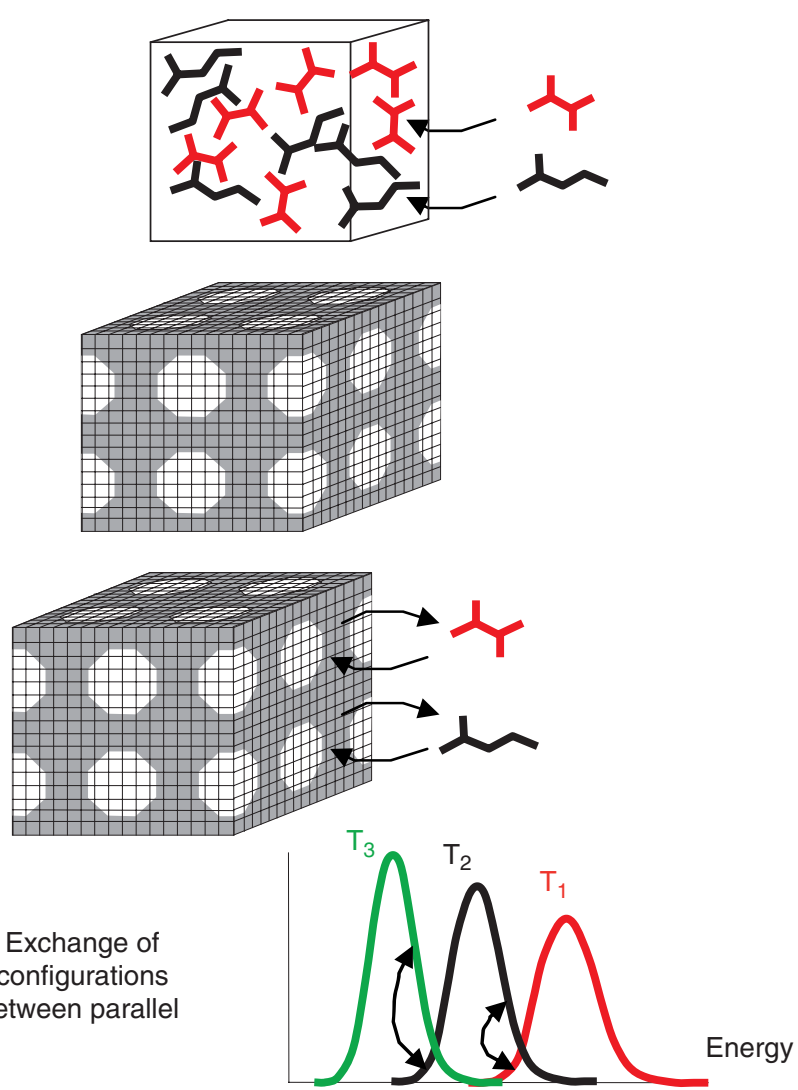

Figure 1

General approach of Monte Carlo simulation of the adsorption in zeolites from non-ideal fluid phases. 
mobile species bear significant charges (cations), dipole moments (thiols, water, etc.) or quadrupole moments $\left(\mathrm{CO}_{2}\right)$.

Polarization energy is not accounted for when purely siliceous forms are considered, because the electric field is small in these cases due to the absence of charge-compensating cations. It is explicitly considered in cation-substituted zeolites, such as faujasites. Electrostatic energy and polarization energy are computed with Ewald summation [27] using the charge distributions obtained by the electronegativity equalization method by Mortier and co-workers [28, 29].

The Monte Carlo moves used to sample efficiently the configuration space in Grand Canonical simulations are as follows:

- rigid body translations;

- rigid body rotations;

- regrowth of flexible molecules, using the Configurational Bias [30, 31] and reservoir bias [9] schemes;

- insertions of new molecules or deletion of existing molecules, using configurational and reservoir bias for linear and branched molecules or a two-step reservoir bias involving a pre-insertion [32] for rigid or cyclic molecules;

- swap, i.e. identity exchange between two molecules;

- jump, i.e. destruction of a molecule at one place and biased insertion at a randomly selected place in the simulation box, using configurational bias or reservoir bias depending on the type of molecule;

- exchange of temperatures or chemical potentials between two parallel simulations, according to the classical parallel tempering scheme [33].

In order to evaluate the chemical potential of every molecular species when adsorption is considered in far from ideal gas conditions, a preliminary NPT simulation of the fluid phase is conducted at the desired equilibrium pressure with biased Widom test insertions (Fig. 1). The GIBBS software used for our calculations allows for Grand Canonical simulations of adsorption and NPT simulations of fluid phases with the same algorithms, so that full consistency is ensured. Among the above moves, jump moves appear to be essential for the efficient finding of equilibrium cationic locations. Compared with our previous investigations [18], they allow for a quicker convergence without requiring exploration of higher temperatures.

\section{APPLICATIONS}

\subsection{Location of Cations in Na Faujasite}

In Figure 2, we show the experimental and simulated distribution of non-framework cations among the different types of crystallographic sites in faujasites with various silicon to aluminium ratios, using the intermolecular potential of Auerbach and co-workers [20]. Thanks to the jump move,

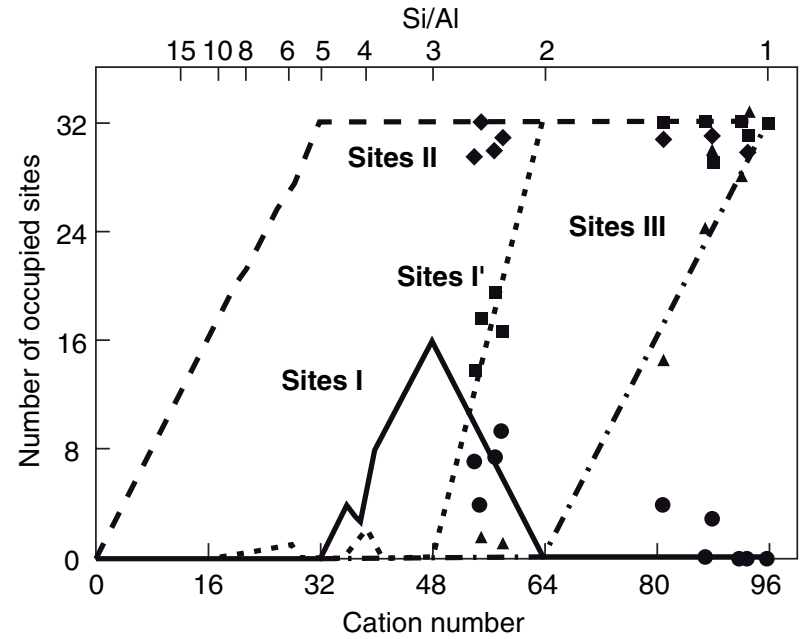

Figure 2

Occupation of cationic sites I, I', II and III in anhydrous sodium faujasites for various numbers of cations per unit cell, i.e. for various $\mathrm{Si} / \mathrm{Al}$ ratios. Continuous lines indicate simulation results [37] for sites I (full lines), I' (dotted lines), II (dashed line) and III (dot-dashed line). Experimental data are indicated by dots (sites I), squares (sites I'), diamonds (sites II) and triangles (sites III).

the sequential filling of sites II, I, I' and III is well described with significantly reduced computational effort. Sites II are first occupied because they are more energetically favorable. Once all the 32 sites II present in a unit cell are occupied, following cations take place in sites I where their energy is higher. There are only 16 sites I, and the next favorable sites are sites I'. However, electrostatic repulsion prevents sites I and I' from being occupied simultaneously. From an energetic standpoint, it is more favorable that the further increase in the number of cations progressively causes sites I to be abandoned, while twice as many sites I' are occupied. When the 32 sites I' are occupied (i.e. when the total number of cations is 64 , including sites II), there are no more cations in sites I. Further cations occupy sites III, which are even less favorable than II, I and I'. Finding this sequence as a result of a simple force field is encouraging for more complex applications involving guest molecules.

\subsection{Adsorption of Alkanes}

In zeolites with low polarity, such as silicalite or ferrierite, the adsorption of hydrocarbons may be described by considering exclusively dispersion and repulsion forces through a Lennard-Jones potential [10]. In this approach, alkanes are treated as chains of united atoms where each $\mathrm{CH}_{2}, \mathrm{CH}_{3}$ or $\mathrm{CH}$ group is treated as a separate Lennard-Jones center, neglecting hydrogens in the same way as in the simulation of 
liquid-vapor equilibrium [31]. A significantly more accurate way of describing vapor-liquid equilibrium is to use anisotropic united atoms (AUA), where hydrogens are not explicitly modeled, but the position of the Lennard-Jones center is offset to account for their influence [24, 34]. Using the AUA model has proved very efficient to describe the adsorption of alkanes in silicalite [13] and ferrierite [15], as illustrated in Figure 3. In this model, the interaction between the zeolitic oxygens and the force centers of the guest molecules is determined from a simple combining rule based on standard Lennard-Jones parameters for the framework oxygens $(\sigma=3.00 \AA, \varepsilon / \mathrm{k}=93.53 \mathrm{~K})$. Thus the model may be used without further calibration to model the adsorption of other compounds in silicalite such as alkenes [14]. The S-shaped adsorption of n-heptane in silicalite seen in Figure 3 may be explained by a detailed analysis of molecular positions $[10,13]$. The lower slope observed at 4 molecules per unit cell, i.e. half of the saturation plateau, is explained by the transition from a favorable adsorption up to four molecules per unit cell in sinusoidal channels, while further filling of straight channels is hampered by the occupancy of intersections. As there is no drastic change in the isosteric heat of adsorption above 4 molecules per unit cell, this effect may be considered mostly entropic.

The application of this model to the adsorption of alkanes in cation-exchanged faujasites is not straightforward. Indeed, it appears that the Lennard-Jones potential alone significantly

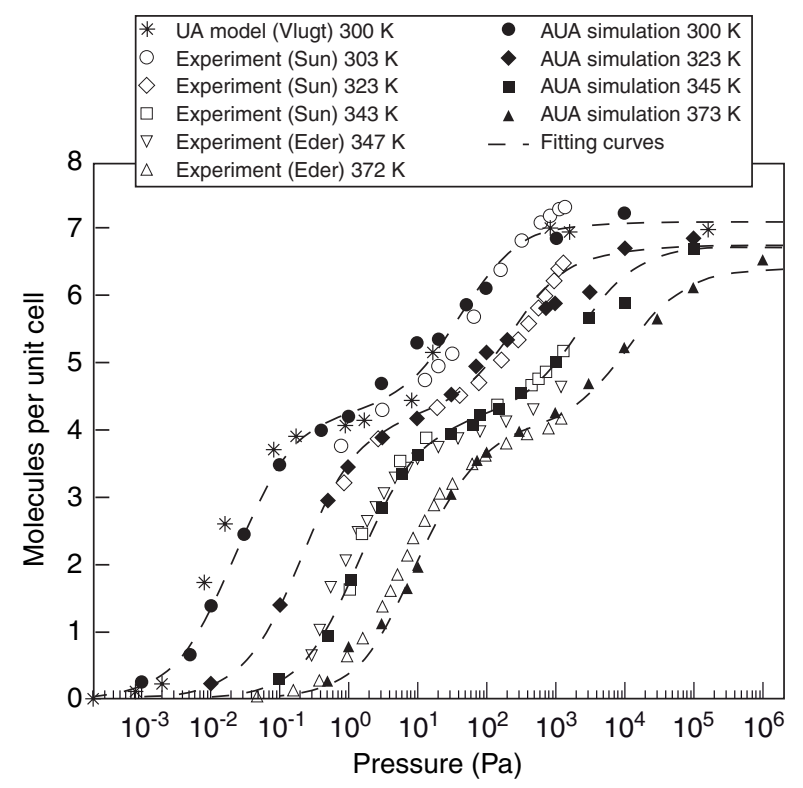

Figure 3

Adsorption isotherms of $n$-heptane in silicalite-1 at 300, 323, 345 and $373 \mathrm{~K}$ after Pascual et al. [13]. Open symbols: experiments [37]; stars: United Atoms model of Vlugt et al. [10]; full symbols: AUA model; dotted lines: Langmuir dual site correlation model. underestimates the attraction energy between alkanes and faujasites. The explanation that we propose for this failure is that the electrostatic field is considerably more important in these zeolites, so that polarization energy cannot be neglected as in silicalite and ferrierite. Faced with this problem, it has been proposed to attribute a very attractive potential to the dispersion-repulsion interactions between cations and guest alkanes [35]. This allows a successful description of adsorption isotherms, but the resulting model is of limited use from an industrial standpoint because it is specific to sodiumexchanged faujasites. The alternative strategy that we propose is to account explicitly for the polarization energy, which can be evaluated by using the average dipole polarizabilities of alkanes [36]. As illustrated by the adsorption isotherms of ethane in $\mathrm{Na}_{52} \mathrm{Y}$ faujasite shown in Figure 4, this approach provides encouraging results without calibrating any new parameter. This might be a general alkane adsorption model, encompassing silicalite, ferrierite and $\mathrm{NaY}$ faujasite in a single theoretical framework with a unique parametrization. Further extension of this line of research to alkanes of higher molecular weight and to $\mathrm{NaX}$ faujasites is under way.

\subsection{Adsorption of Water}

Using the simple TIP4P model of water [23] and the same cation force field as above [20], it is possible to simulate the adsorption of water in sodium-exchanged faujasites. For this purpose, we describe dispersion-repulsion energy between water and framework oxygens with the same model as alkanes. As it is based on a combining rule between TIP4P and Pascual's parameters [13] no specific parameter has to be calibrated. Electrostatic energy is computed by the simple application of Coulomb's law with the same zeolite charges as in the above investigation of cation positions, and TIP4P original charges. Given the simplicity of this approach, the outcome of this simulation is surprisingly good, as illustrated by the adsorption isotherm of water in $\mathrm{Na}_{52} \mathrm{Y}$ faujasite shown in Figure 5. In agreement with experimental findings from X-ray diffraction, cations are found to move from sites I to sites I' when water is adsorbed. The reason behind this motion of cations is that water in sodalite cages attract cations in sites I' through dipolar interactions which are much weaker if cations stay in sites I. This kind of understanding is encouraging for the further investigation of water influence upon the adsorption selectivity of aromatic isomers in faujasites.

\subsection{Adsorption of Alkanethiols from Natural Gas}

Alkanethiols (R-SH, where R is methyl, ethyl or propyl) are trace components of natural gas that are highly poisonous and strong-smelling. Adsorption is considered as one of the possible ways of removing these compounds from natural 


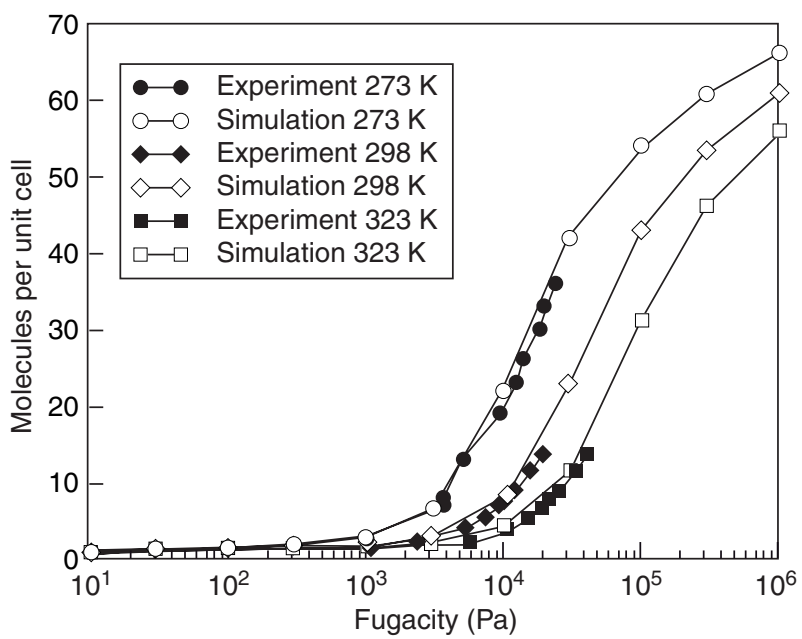

Figure 4

Adsorption isotherms of ethane in $\mathrm{Na}_{52} \mathrm{Y}$ faujasite at 273, 298 and $323 \mathrm{~K}$ from simulations and from the experimental data of [38].

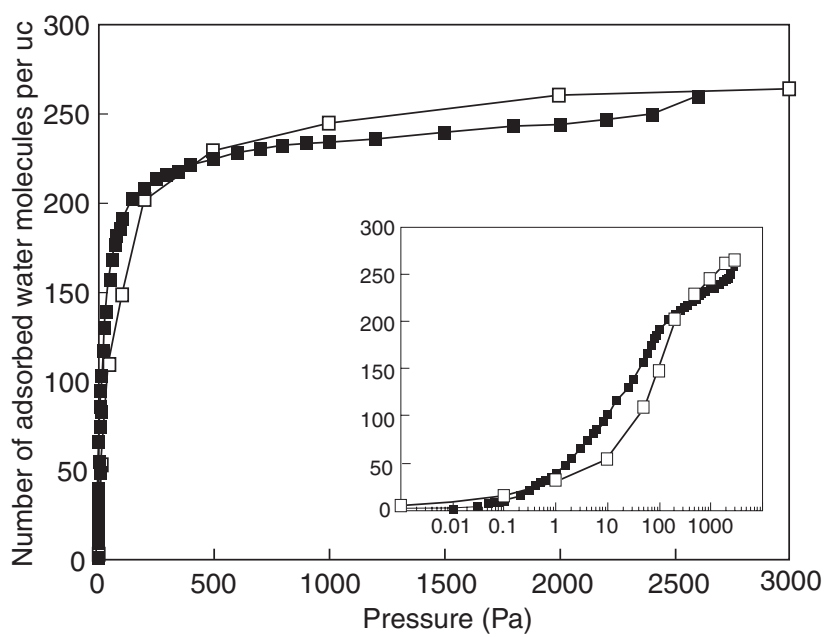

Figure 5

Adsorption isotherm of water in $\mathrm{Na}_{52} \mathrm{Y}$ faujasite at $300 \mathrm{~K}$. Open symbols: simulation results; full symbols: experiments [39].

\section{TABLE 1}

Simulation of the adsorption of a dehydrated natural gas containing traces of methanethiol and ethanethiol in NaX Faujasite at $298 \mathrm{~K}$ for two pressures ( 0.1 and $5 \mathrm{MPa}$ )

\begin{tabular}{|c|c|c|c|c|c|c|c|}
\hline & & \multicolumn{3}{|c|}{$\mathrm{P}=0.1 \mathrm{MPa}$} & \multicolumn{3}{|c|}{$\mathrm{P}=5 \mathrm{MPa}$} \\
\hline & $\begin{array}{l}\text { Molar fraction } \\
\text { of the gas phase }\end{array}$ & $\begin{array}{c}\text { Chemical } \\
\text { potential/k }\end{array}$ & $\begin{array}{l}\text { Molecules } \\
\text { per unit cell }\end{array}$ & $\begin{array}{c}\text { Molar fraction } \\
\text { in adsorbed } \\
\text { phase }\end{array}$ & $\begin{array}{c}\text { Chemical } \\
\text { potential/k } \\
(\mathrm{K})\end{array}$ & $\begin{array}{l}\text { Molecules } \\
\text { per unit cell }\end{array}$ & $\begin{array}{c}\text { Molar fraction } \\
\text { in adsorbed } \\
\text { phase }\end{array}$ \\
\hline Methanethiol & $50 \mathrm{ppm}$ & -6117.5 & 23 & 0.130 & -4951.75 & 20 & 0.098 \\
\hline Ethanethiol & 100 ppm & -5910.98 & 6 & 0.034 & -4745.20 & 6 & 0.029 \\
\hline Toluene & 100 ppm & -5910.98 & $<1$ & $<0.006$ & -4745.2 & $<1$ & $<0.005$ \\
\hline$n$-heptane & $1000 \mathrm{ppm}$ & -5431.36 & - & $<0.006$ & -4265.6 & $<1$ & $<0.005$ \\
\hline $\mathrm{CO}_{2}$ & 0.02 & -4332.08 & 1 & 0.006 & -3166.3 & $<1$ & $<0.005$ \\
\hline propane & 0.03 & 4332.08 & $<1$ & $<0.006$ & -3166.3 & $<1$ & $<0.005$ \\
\hline ethane & 0.10 & -4059.02 & $<1$ & $<0.006$ & -2897.6 & $<1$ & $<0.005$ \\
\hline methane & 0.85 & -3197.69 & $<1$ & $<0.006$ & -2053.84 & $<1$ & $<0.005$ \\
\hline $\mathrm{H}_{2} \mathrm{O}$ & $60 \mathrm{ppm}$ & -6063.2 & 144 & 0.818 & -4897.4 & 177 & 0.863 \\
\hline $\mathrm{H}_{2} \mathrm{~S}$ & $4 \mathrm{ppm}$ & -6870.2 & $<1$ & $<0.006$ & -5704.42 & $<1$ & $<0.005$ \\
\hline \multicolumn{2}{|l|}{ Total } & \multicolumn{3}{|c|}{176} & \multicolumn{3}{|c|}{205} \\
\hline
\end{tabular}

gas, as required by existing regulations. They are polar compounds for which an AUA model has been proposed [26], using electrostatic charges determined from ab initio simulations. In order to simulate the adsorption of alkanethiols, we can thus use the same approach as followed above with water, i.e. dispersion-repulsion energy from Pascual's approach [13] and electrostatic energy from Coulomb's law. As shown in a recent publication [4], this allows the description of the adsorption isotherms of ethanethiol in reasonable agreement with experimental data. When adsorption from a multicomponent gas mixture under high pressure is considered, the same Grand Canonical approach can be used, provided chemical potentials are determined appropriately (Fig. 1). Doing this, the same approach as above is used for water and hydrocarbons. In Table 1 , we provide a typical result of such simulations in $\mathrm{NaX}$ faujasite for a dehydrated natural gas containing $98 \%$ of hydrocarbon gases, 150 ppm of alkanethiols and also traces of other compounds (water, 
liquid hydrocarbons and acid gases). Due to the importance of its electrostatic interactions with the zeolite, water is strongly adsorbed, despite its low concentration in the gas (60 ppm). Alkanethiols are second among adsorbed products, which is logical as their electrostatic interactions are weaker than water. The other species are not significantly adsorbed, although they are by far major in the fluid phase. These results are preliminary because polarization energy was not accounted for, and aromatics were considered non-polar. Nevertheless, experimental investigation has shown that simulation has identified the major trends well in this complex system, and this is encouraging for further use of simulation.

\section{CONCLUSION}

Simulating the adsorption of hydrocarbons and polar compounds in zeolites, as required by the applications to the development of separation processes, is a difficult task. Indeed, adsorption equilibria involve both entropic contributions, as illustrated by the shape of the isotherm of alkanes in silicalite, and energetic contributions which explain the distribution of cations and the strong adsorption of polar compounds, as illustrated by the case of water and alkanethiols. Thanks to a careful description of the various interactions involved (guest-zeolite, guest-guest and cation-zeolite) it now seems feasible to propose a consistent approach to treat a large range of microporous aluminosilicates and of guest molecules. For this purpose, it appears necessary to consider dispersion, repulsion, electrostatic and polarization contributions to the energy, but some of these contributions may be neglected in several cases: for instance, electrostatic energy is not required to consider alkane adsorption, and polarization energy can be neglected when considering alkane adsorption in silicalite.

This simple approach still requires further testing and improvement in several ways. A first line of improvement is to extend the comparison with experimental data to the adsorption of hydrocarbons in sodium-exchanged faujasites, for which numerous data are available. A second research avenue is to extend the simulation of cation-zeolite interactions to other cations such as $\mathrm{K}^{+}, \mathrm{Ba}^{++}, \mathrm{Cs}^{+}$, etc. In this respect, the investigation of the subtle influence of cation distribution and polar species on the adsorption selectivity of hydrocarbon isomers is a particularly interesting challenge.

\section{REFERENCES}

1 Ruthven, D.M. (1984) Principles of adsorption and adsorption processes, Wiley, New York.

2 Baerlocher, C., Meier, W.M. and Olson, D.H. (2001) Atlas of zeolite framework types, 5th edn., Elsevier, Amsterdam.

3 Mortier, W. (1982) Compilation of extra Framework sites in zeolites., Butterworth, Guildford.
4 Ungerer, P., Tavitian, B. and Boutin, A. (2005) Applications of molecular simulation in the oil and gas industry - Monte Carlo methods, Editions Technip, Paris.

5 Snurr, R.Q., Bell, A.T. and Theodorou, D.N. (1993) Prediction of adsorption of aromatic hydrocarbons in silicalite from Grand Canonical Monte Carlo Simulations with biased insertions, J. Phys. Chem., 97, 13742.

6 Smit, B. (1995) Grand Canonical Monte Carlo simulations of chain molecules: adsorption isotherms of alkanes in zeolites, Mol. Phys., 85, 153.

7 Smit, B. (1995) Simulating the adsorption isotherms of methane, ethane, and propane in the zeolite silicalite., J. Phys. Chem., 99, 5597-5603.

8 Nicholson, D. and Parsonage, N.G. (1982) Computer simulation and the statistical mechanics of adsorption, Academic Press, New York, USA.

9 Macedonia, M.D. and Maginn, E.J. (1999) A biased grand canonical Monte Carlo method for simulating adsorption using all-atom and branched united atom models, Mol. Phys., 96, 1375-1390

10 Vlugt, T.J.H., Krishna, R. and Smit, B. (1999) Molecular simulations of adsorption isotherms for linear and branched alkanes and their mixtures in silicalite, J. Phys. Chem. B, 103, 1102-1118.

11 Dubbeldam, D., Calero, S., Vlugt, T.J.H., Krishna, R., Maesen, T.L.M. and Smit, B. (2004) United atom force field for alkanes in nanoporous materials, J. Phys. Chem B, 108, 12301-12313.

12 Schenk, M., Calero, S., Maesen, T.L.M., Vlugt, T.J.H., Benthem, L.L.V., Verbeek, M.G., Schnell, B. and Smit, B. (2003) Shape selectivity through entropy, J. Catal., 214, 88-99.

13 Pascual, P., Pernot, P., Ungerer, P., Tavitian, B. and Boutin, A. (2003) Development of a transferable guest-host force field for adsorption hydrocarbons in zeolites. Reinvestigation of alkanes adsorption in silicalite by grand canonical Monte Carlo simulation, Phys. Chem. Chem. Phys., 5, 3684.

14 Pascual, P., Ungerer, P., Tavitian, B. and Boutin, A. (2004) Development of a transferable guest-host force field for adsorption of hydrocarbons in zeolites. II. Prediction of alkenes adsorption and alkane/alkene selectivity in silicalite, J. Phys. Chem. B, 108, 393-398.

15 Pascual, P., Boutin, A., Ungerer, P., Tavitian, B. and Fuchs, A.H. (2004) Adsorption of hydrocarbons in zeolites from molecular simulations. The alkane-ferrierite system revisited, Phys. Chem. Chem. Phys., 6, 2015-2017.

16 Lachet, V., Boutin, A., Tavitian, B. and Fuchs, A.H. (1999) Molecular simulation of p-xylene and m-xylene adsorption in Y zeolites. Single components and binary mixtures study, Langmuir, 15, 8678-8685.

17 Lagache, M., Ungerer, P., Boutin, A. and Fuchs, A.H. (2001) Prediction of thermodynamic derivative properties of fluids by Monte Carlo simulation, Phys. Chem. Chem. Phys., 3, 4333-4339.

18 Beauvais, C., Guerrault, X., Coudert, F.-X., Boutin, A. and Fuchs, A.H. (2004) Distribution of sodium cations in faujasite-type zeolite: a canonical parallel tempering simulation study, J. Phys. Chem. B, 108, 399-404.

19 Beauvais, C., Boutin, A. and Fuchs, A.H. (2004) A numerical evidence for nonframework cation redistribution upon water adsorption in Faujasite zeolite, Phys. Chem. Chem. Phys., 5, 1-7.

20 Jaramillo, E. and Auerbach, S.M. (1999) New force field for Na cations in faujasite-type zeolites, J. Phys. Chem. B, 103, 9589-9594. 
21 Jorgensen, W.L., Laird, E.R., Nguyen, T.B. and TiradoRives, J. (1993) Monte Carlo Simulations of pure liquid substituted benzenes with OPLS potential functions, J. Comput. Chem., 14, 206-215.

22 Harris, J.G. and Yung, K.H. (1995) Carbon dioxide's liquidvapor coexistence curve and critical properties as predicted by a simple molecular model, J. Phys. Chem., 99, 12021-12024.

23 Jorgensen, W.L., Chandrasekhar, J. and Madura, J.D. (1983) Comparison of simple potential functions for simulating liquid water, J. Chem. Phys., 79, 926-935.

24 Ungerer, P., Beauvais, C., Delhommelle, J., Boutin, A. Rousseau, B. and Fuchs, A.H. (2000) Optimization of the anisotropic united atoms intermolecular potential for n-alkanes, J. Chem. Phys., 112, 5499-5510.

25 Bourasseau, E., Ungerer, P., Boutin, A. and Fuchs, A.H (2002) Monte Carlo simulation of branched alkanes and long chain n-alkanes with anisotropic united atoms intermolecular potential, Mol. Simulat., 28, 317-336.

26 Delhommelle, J., Tschirwitz, C., Ungerer, P., Granucci, G., Millié, P., Pattou, D. and Fuchs, A.H. (2000) Derivation of an optimized potential model for phase equilibria (OPPE) for sulfides and thiols, J. Phys. Chem. B, 104, 4745-4753.

27 Allen, M.P. and Tildesley, D.J. (1987) Computer simulation of liquids, Oxford Science Publications, Oxford.

28 Lievens, J.L., Mortier, W.J. and Verduijn, J.P. (1992) Influence of the framework composition on the cation-site energy: the structures of dehydrated NaxHGaY $(x=54,36$ and 21) zeolites, J. Phys. Chem, 96, 5473-5477.

29 Mortier, W.J., Ghosh, S.K. and Shankar, S. (1986) Electronegativity equalization method for the calculation of atomic charges in molecules, J. Am. Chem. Soc., 108, 4315-4320.
30 de Pablo, J.J., Laso, M. and Suter, U.W. (1992) Estimation of the chemical potential of chain molecules by simulation, J. Chem. Phys., 96, 6157.

31 Smit, B., Karaborni, S. and Siepmann, J.I. (1995) Computer simulation of vapor-liquid phase equilibria of n-alkanes, J. Chem. Phys., 102, 2126.

32 Bourasseau, E., Ungerer, P. and Boutin, A. (2002) Prediction of equilibrium properties of cyclic alkanes by Monte Carlo simulation - new anisotropic united atoms potential - new transfer bias method, J. Phys. Chem. B, 106, 5483-5491.

33 Faller, R., Yan, Q. and de Pablo, J.J. (2002) Multicanonical parallel tempering, J. Chem. Phys., 116, 5419.

34 Toxvaerd, S. (1990) Molecular dynamics calculation of the equation of state of alkanes, J. Chem. Phys., 93, 4290.

35 Calero, S., Dubbeldam, D., Krishna, R., Smit, B., Vlugt, T.J.H., Denayer, J.F.M., Martens, J.A. and Maesen, T.L.M (2004) Understanding the role of sodium during adsorption: A force field for alkanes in sodium-exchanged faujasites, J. Am. Chem. Soc., 126, 11377-11386.

36 Delhommelle, J., Millié, P. and Fuchs, A.H. (2000) On the role of the definition of potential models in Gibbs ensemble simulations of the $\mathrm{H}_{2} \mathrm{~S}$-n-pentane mixture, Mol. Phys., 98, 1895.

37 Sun, M.S., Talu, O. and Shah, D.B. (1996) Adsorption equilibria of C5-C10 normal alkanes in silicalite crystals., J.Phys. Chem., 100, 17276.

38 Hampson, J.A. and Rees, L.V.C. (1993) J. Chem. Soc. Trans., 89, 3169-3176.

39 Moïse, J.C., Bellat, J.P. and Méthivier, A. (2001) Micropor. Mesopor. Mat., 43, 91-101.

Final manuscript received in June 2006 